\title{
Correction: The genetic history of France
}

Aude Saint Pierre (1) - Joanna Giemza - Isabel Alves - Matilde Karakachoff • Marinna Gaudin • Philippe Amouyel • Jean-François Dartigues • Christophe Tzourio - Martial Monteil • Pilar Galan · Serge Hercberg • lain Mathieson • Richard Redon • Emmanuelle Génin (1) - Christian Dina (1)

Published online: 11 March 2020

(c) The Author(s), under exclusive licence to European Society of Human Genetics 2020

\section{Correction to: European Journal of Human Genetics} https://doi.org/10.1038/s41431-020-0584-1

Upon publication of the original article, the authors forgot to acknowledge the Nantes Bioinformatics Core Facility
GenoBird. This has now been included in the Acknowledgements section of original article and is also listed below: "We are most grateful to the Bioinformatics Core Facility of Nantes (BiRD, Biogenouest) for its technical support". 